
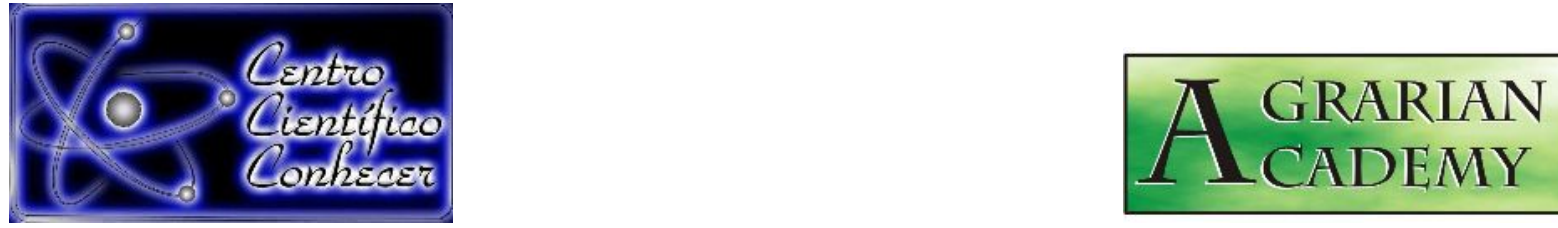

\title{
QUALIDADE DA MADEIRA DE HEVEA BRASILIENSIS VISANDO A PRODUÇÃO DE CELULOSE E PAPEL
}

Douglas Lamounier Faria'; Carolina Aparecida Santos ${ }^{1}$; Ana Carolina Corrêa Furtini ${ }^{1}$;

Lourival Marin Mendes ${ }^{2}$; José Benedito Guimarães Júnior ${ }^{2}$

1. Pós-Graduando em Engenharia de Biomateriais - Departamento de Ciências

Florestais - Universidade Federal de Lavras - Lavras/MG -

Brasil

2. Professor Dr. do Programa de pós-graduação em Engenharia de Biomateriais Universidade Federal de Lavras - Lavras/MG -

Brasil

E-mail para correspondência: douglas.lamounier@yahoo.com

Recebido em: 02/06/2019 - Aprovado em: 15/06/2019 - Publicado em: 22/07/2019

DOI: 10.18677/Agrarian_Academy_2019a29

\section{RESUMO}

O objetivo deste trabalho foi avaliar a espécie madeireira Hevea brasiliensis (seringueira) visando o uso para a fabricação de celulose e papel. Foram cortadas três árvores do clone $\mathrm{Pb} 235$. Obteve-se discos das posições 0, 25, 50, 75 e 100\% da altura comercial. Foi realizada análise química, física e anatômica da madeira. A espécie apresentou valores médios de holocelulose de $80,83 \%$, compatível com a madeira de Eucalipto tradicionalmente empregada na produção de celulose e papel. Em relação aos valores obtidos de dimensão média das fibras (comprimento, largura, diâmetro do lume e espessura da parede), estes foram próximos aos encontrados na literatura. Com relação ao Índice de Runkel, foi possível classificar a fibra de Hevea brasiliensis como boa para fabricação de papel, mas com relação à Fração Parede, a fibra se encontra acima do limite. Já para coeficiente de flexibilidade, o mesmo encontra-se abaixo do recomendado e o índice de enfeltramento encontra-se na faixa ideal. A densidade básica média obtida foi de $0,541 \mathrm{~g} / \mathrm{cm}^{3}$, valor próximo ao encontrado na literatura, o que possibilitou a sua classificação como madeira de média densidade. Após análise dos resultados foi possível considerar a madeira de Hevea brasiliensis como uma espécie promissora para fabricação de celulose e papel.

PALAVRAS-CHAVE: Componentes químicos e anatômicos; Polpa celulósica; Polpação. 


\title{
QUALITY OF HEVEA BRASILIENSIS WOOD AIMING THE PRODUCTION OF CELLULOSE AND PAPER
}

\begin{abstract}
The aim of this work was to evaluate the wood species Hevea brasiliensis for its use in the manufacture of cellulose and paper. Three trees of the $\mathrm{Pb} 235$ clone were cut. Discs of positions $0,25,50,75$ and $100 \%$ of the commercial height were obtained. Chemical, physical and anatomical analysis of the wood was performed. The species presented average values of holocellulose of $80.83 \%$, compatible with Eucalyptus wood traditionally used in cellulose and paper production. In relation to the obtained values of average size of the fibers (length, width, lumen diameter and wall thickness), these were close to those found in the literature. Regarding the Runkel Index, it was possible to classify the fiber of Hevea brasiliensis as good for papermaking, but with respect to the Wall Fraction, the fiber is above the limit. As for the coefficient of flexibility, it is below the recommended level and the index of enfeltramento is in the ideal range. The average basic density obtained was 0.541 $\mathrm{g} / \mathrm{cm}^{3}$, value close to that found in the literature, which allowed its classification as medium density wood. After analysis of the results it was possible to consider Hevea brasiliensis wood as a promising species for cellulose and paper production.
\end{abstract}

KEYWORDS: Cellulosic pulp; Chemical and anatomical components; Pulping.

\section{INTRODUÇÃO}

Embora seja uma espécie de origem amazônica, o Brasil se destaca no plantio de Hevea brasiliensis nas regiões do noroeste de São Paulo, o oeste do Triângulo Mineiro e o nordeste do Mato Grosso do Sul, região que alia ótimas condições climáticas, alta densidade demográfica e um grande mercado consumidor. Hoje, São Paulo é o maior produtor nacional de borracha natural. Com base nos dados da Produção Agrícola Municipal (PAM) publicado pelo Instituto Brasileiro de Geografia e Estatística (IBGE, 2017), para uma produção nacional de borracha de 315.629 toneladas, São Paulo contribuiu com 182.981 toneladas, ou seja, 58\%, seguido pelos Estados da Bahia, com 40.314 t (12,77\%), de Mato Grosso com 23.751 t, (7,52\%), Minas Gerais com 25.670 t (8,13\%), Goiás com 18.912 t (6\%), e Espírito Santo com 10.116 t (3,20\%).

A madeira é um material de origem biológica que apresenta propriedades físicas e mecânicas variáveis entre as espécies e dentro de uma mesma espécie, sendo matéria-prima indispensável em aplicações na construção civil, indústria moveleira, energia da biomassa, indústria de papel e celulose, dentre outras. Na sua forma maciça e em dimensões maiores, a madeira tornou-se, ao decorrer dos anos, um material difícil de ser encontrado devido à constante supressão de florestas nativas e à legislação ambiental vigente. Assim, os setores que a utilizam buscaram novas alternativas para um aproveitamento mais racional e que pudessem diminuir suas limitações de uso, a exemplo da produção dos painéis reconstituídos de madeira, como compensados, aglomerados de partículas, sarrafeados, MLC (Madeira Laminada Colada), entre outros (SEGUNDINHO et al., 2017; ANDRADE et al., 2018; PINATI et al., 2018).

Estudar a estrutura física e anatômica de cada espécie de madeira é de suma importância, uma vez que suas características influenciam no comportamento tecnológico quando em uso e refletem diretamente no processo de industrialização (BONDUELLE et al., 2015; FREITAS et al., 2015; GALLIO et al., 2016; GIL et al., 2018). Segundo Burger e Richter (1991), o estudo anatômico da madeira é o estudo 
de diversos tipos de células que constituem o lenho, suas funções, organização e peculiaridades estruturais com os objetivos de conhecer a madeira visando seu emprego correto; identificar espécies; distinguir lenhos aparentemente idênticos; predizer utilizações adequadas com base nas características anatômicas; prever e compreender o comportamento da madeira no que diz respeito à utilização. Lima et al. (2014) enfatizam que as características anatômicas de cada espécie influenciam o comportamento tecnológico e apresentam variação entre as espécies e dentro da mesma espécie.

Para França et al. (2015) as dimensões, a frequência e a distribuição dos constituintes anatômicos, afetam as propriedades físicas e mecânicas da madeira. Estruturas como a espessura e o comprimento da parede celular estão relacionados com a resistência das fibras celulósicas e afetam as propriedades físicas (estabilidade dimensional e densidade). Cabe salientar que as propriedades mecânicas apresentam uma associação significativa com muitas características anatômicas, em especial aquelas que dizem respeito às fibras e vasos.

Segundo Gama et al. (2014), a densidade da madeira varia entre espécies, entre indivíduos e procedências da mesma espécie e dentro da árvore, tanto no sentido longitudinal, ou seja, da base para o topo, como no sentido radial da medula para a casca, sendo, do ponto de vista da utilização tecnológica da madeira, extremamente importante o estudo da variação nesses sentidos.

Diante disso, o conhecimento das características tecnológicas da madeira, tais como, densidade básica, composição química e morfologia das fibras é de grande importância para determinação da qualidade final do papel e celulose, uma vez que essas propriedades se entrelaçam com os parâmetros como Índice de Runkel, Coeficiente de Flexibilidade, Índice de Enfeltramento e Fração Parede (VIVIAN et al., 2015).

Neste sentido o objetivo deste trabalho foi avaliar a densidade básica, componentes químicos e estruturas anatômicas da espécie Hevea brasiliensis visando a produção de celulose e papel.

\section{MATERIAL E MÉTODOS}

Para realização desse estudo foram abatidas seis árvores de seringueira (Hevea brasiliensis) clone $\mathrm{Pb} 235$ com aproximadamente 20 anos e diâmetro médio do fuste à altura de $1,30 \mathrm{~m}$ do solo (DAP) de $40 \mathrm{~cm}$ num plantio florestal localizado no campus da Universidade Federal de Lavras (UFLA), situada em Lavras, Sul de Minas Gerais. Salienta-se que as árvores se encontravam com DAP na faixa considerada ideal para produção de celulose e papel, entre 15 e $40 \mathrm{~cm}$, como descrito por Garbin et al. (2017). Para cada árvore retirou-se discos em 0, 25, 50, 75 e $100 \%$ da altura comercial. Em seguida, os discos foram acondicionados em câmara de climatização a uma temperatura de $22 \pm 2{ }^{\circ} \mathrm{C}$ e $65 \pm 5 \%$ de umidade relativa.

Após estabilização da umidade, os discos foram divididos em quatro cunhas (Figura 1), em que duas cunhas opostas foram utilizadas para obtenção da densidade básica e as outras duas cunhas opostas foram utilizadas para análise anatômica e química. 


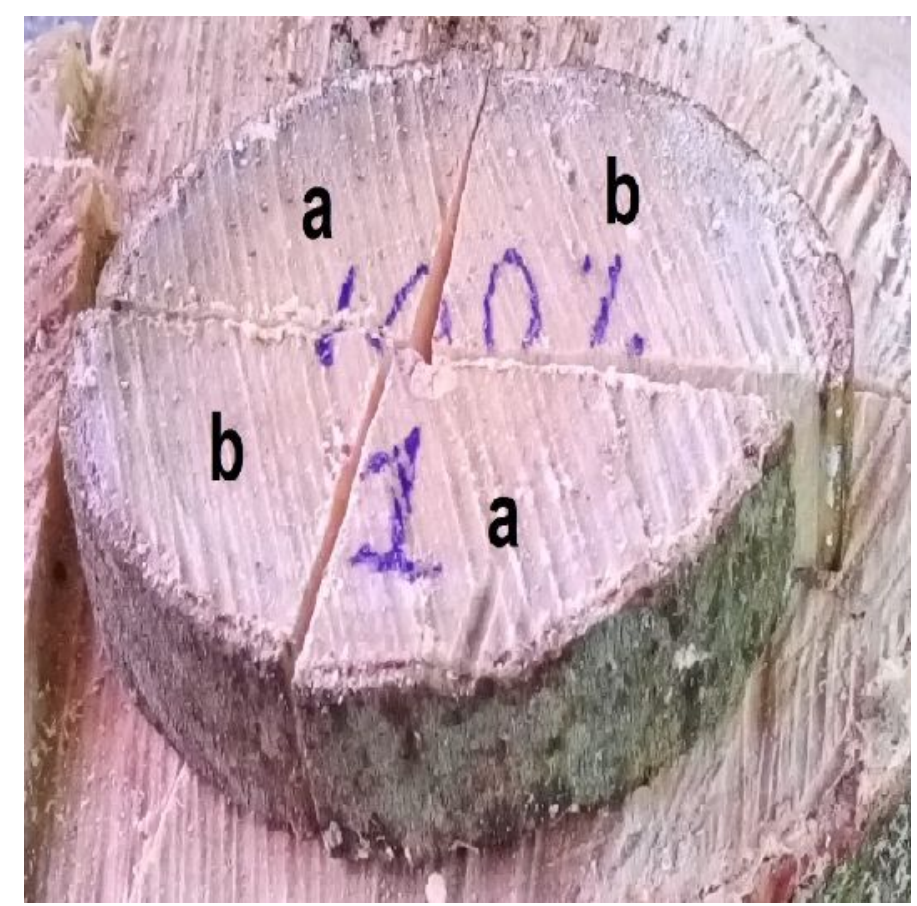

FIGURA 1. Divisão dos discos em cunhas. a) Cunhas empregadas para obtenção da densidade básica. b) Cunhas utilizadas para análise anatômica e química.

Para determinação da densidade básica no sentido base-topo, foram obtidas amostras nas dimensões 2,0 × 3,0 × 5,0 cm de cada cunha. Após a saturação das amostras em água desionizada à temperatura média de $20 \stackrel{\circ}{\circ}$, foi determinada a densidade básica das cunhas de cada disco tendo como diretriz a norma NBR 11941 (ABNT, 2003).

As cunhas destinadas a essa análise foram reduzidas a cavacos. Para a dissociação de seus elementos anatômicos foi realizado o processo de maceração. O preparo das lâminas se deu com base no procedimento descrito por Burger e Richter (1991).

A mensuração dos constituintes celulares foi realizada com o auxílio do software Wincel Regent PRO, sob uma base amostral de 30 medições para cada característica. As mensurações e descrições foram segundo a lista de características microscópicas de angiospermas do International Association Of Wood Anatomy Committee (IAWA, 1989). A partir dos valores mensurados do diâmetro da fibra e do diâmetro do lúmen, calculou-se a espessura da parede da fibra, sendo expressa pela diferença entre o diâmetro da fibra e o diâmetro do lúmen.

De posse dos resultados das dimensões das fibras calculou-se a média para as árvores e as relações entre as dimensões das fibras por meio do índice de Runkel, expresso pelo quociente da espessura da parede celular pelo diâmetro do lúmen; fração parede, expresso pela espessura da parede celular da fibra dividida pela largura da fibra; coeficiente de flexibilidade, expresso pelo quociente entre o diâmetro da fibra e a largura da mesma; e índice de enfeltramento, expresso pelo quociente do comprimento da fibra pela largura da mesma.

Após a moagem em moinho tipo Willey, a serragem foi separada em peneiras sobrepostas de $40(0,420 \mathrm{~mm})$ e 60 mesh $(0,250 \mathrm{~mm})$, sendo utilizada para a análise apenas a fração retida na peneira de 60 mesh. A determinação dos componentes químicos foram: Extrativos totais - NBR 14853 (2010); lignina insolúvel - NBR 7989 
(2010); cinzas - NBR 13999 (2017). O conteúdo de holocelulose foi obtido subtraindo a soma dos demais componentes considerando um total de $100 \%$.

Os resultados foram submetidos à análise estatística por meio de ANOVA. Rejeitada a hipótese de nulidade, foi aplicada a comparação de médias por meio do teste Tukey a $5 \%$ de significância. Todos os testes foram efetuados no programa Sisvar 5.6.

\section{RESULTADOS E DISCUSSÃO}

As dimensões médias das fibras da madeira de Hevea brasiliensis estão apresentadas na Tabela 1.

TABELA 1. Medidas descritivas das dimensões das fibras de Hevea brasiliensis.

\begin{tabular}{ccccc} 
& $\mathrm{C}(\mathrm{mm})$ & $\mathrm{L}(\mathrm{m})$ & $\mathrm{DL}(\mathrm{m})$ & $\mathrm{EP}(\mathrm{m})$ \\
\hline Média & 1,35 & 24,96 & 13,46 & 5,75 \\
DP & 0,21 & 4,58 & 3,75 & 1,45 \\
CV $(\%)$ & 15,55 & 18,22 & 27,86 & 25,21 \\
\hline
\end{tabular}

C - comprimento das fibras; L - largura das fibras; DL - diâmetro do lume das fibras; EP - espessura da parede das fibras. DP - desvio padrão; CV - coeficiente de variação.

O comprimento médio das fibras analisadas foi de $1,35 \mathrm{~mm}$ para as fibras provenientes da espécie em estudo. Segundo Benites et al. (2015), o comprimento das fibras interfere na resistência do papel ao rasgo, sendo as fibras longas mais resistentes. Fibras longas possibilitam o maior entrelaçamento das mesmas, favorecendo o aumento da resistência do papel. De acordo com Robert (2007), as fibras celulósicas são classificadas de acordo com o comprimento em longa (2 a 5 $\mathrm{mm}$ ) e curta $(0,5$ a $1,5 \mathrm{~mm})$. Os resultados observados nesse estudo colocam as fibras analisadas como fibras curtas. A celulose de fibra longa é mais resistente, já a de fibra curta possui maior capacidade absorvente. Ramos et al. (2018) avaliando a anatomia do lenho de Hevea brasiliensis obtiveram comprimento médio das fibras de $1,26 \mathrm{~mm}$, valores próximos aos observados nesse estudo.

Nota-se que as fibras de Hevea brasiliensis apresentaram largura média das fibras de 24,96 $\mu \mathrm{m}$. Para Benites et al. (2015), a largura das fibras interfere diretamente no coeficiente de flexibilidade e no índice de enfeltramento, em que valores maiores de largura, reduzem o valor dos índices. Tal redução pode predizer que o papel produzido a partir das mesmas apresentará baixa resistência ao rasgo e ao arrebentamento. Ramos et al. (2018) encontraram largura média das fibras de 32 $\mathrm{m}$, resultados próximos aos obtidos nesse estudo.

A espessura média da parede da fibra de Hevea brasiliensis foi de 5,75 $\mu \mathrm{m}$. Paredes mais espessas tendem a aumentar a rigidez e a aspereza da fibra, o que gera folhas mais encorpadas, indicadas para uso em papéis absorventes de alto volume específico, também chamados de papel tissue (MOKFIENSKI et al., 2008). Ramos et al. (2018) observaram valores similares ao deste estudo avaliando a mesma espécie obtendo espessura média de parede de $5 \mu \mathrm{m}$. Em comparação com a espécie Anadenanthera macrocarpa, a mesma apresenta espessura de parede de 5,49 m (BENITES et al., 2015). Dessa forma, a espessura das fibras analisadas ficou, em média, próxima à dessa espécie.

Boschetti et al. (2015) e Baldin et al. (2017) enfatizam que a caracterização anatômica da madeira, em especial os valores referentes às fibras, são de suma importância objetivando-se previsões sobre o comportamento do papel e celulose em condições operacionais de processo. 
A Figura 2 apresentada abaixo mostra valores médios para os principais constituintes anatômicos para a espécie Hevea brasiliensis.
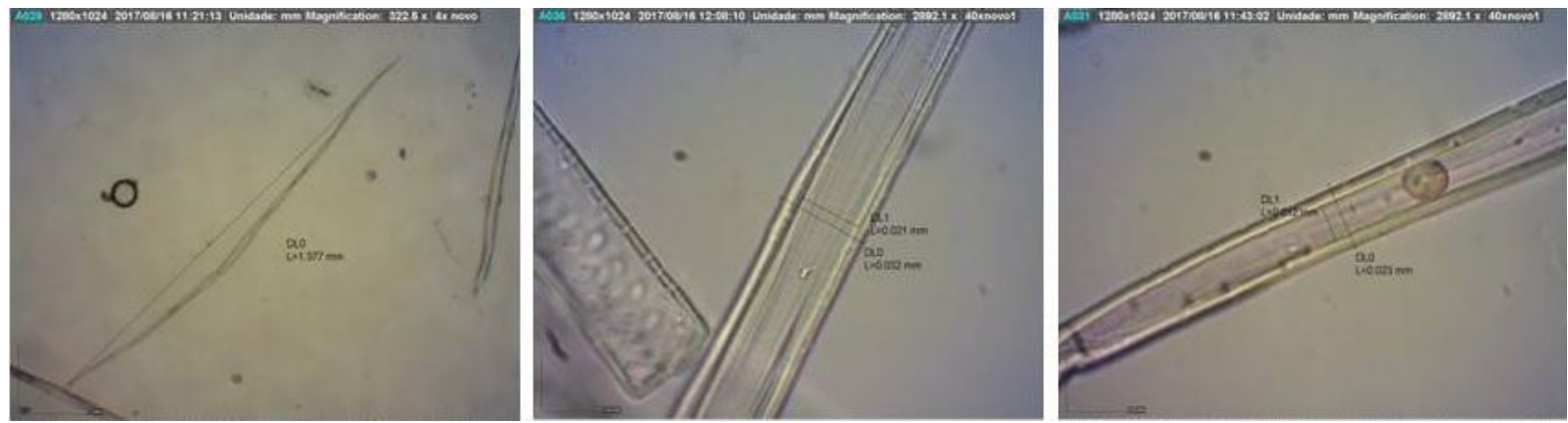

FIGURA 2. a) Comprimento observado para uma fibra; b) Espessura observada da fibra e diâmetro do lume; c) Espessura da parede celular.

Diante das dimensões das fibras de Hevea brasiliensis, as relações entre estas dimensões são apresentadas na Tabela 2.

TABELA 2. Relações entre as dimensões das fibras de Hevea brasiliensis.

\begin{tabular}{ccccc}
\hline Espécie & IR & FP (\%) & CF (\%) & IE \\
\hline $\begin{array}{c}\text { Hevea } \\
\text { brasiliensis }\end{array}$ & 0,854 & 46,07 & 53,92 & 54,08 \\
\hline
\end{tabular}

IR - índice de Runkel; FP - fração parede; CF - coeficiente de flexibilidade; IE - índice de enfeltramento.

De acordo com os resultados apresentados acima na Tabela 2, as fibras de Hevea brasiliensis são classificadas pelo Índice de Runkel como boa para fabricação de papel, uma vez que Paula (1999) estabeleceu que a fibra com índice até 0,25 é considerada excelente; 0,25 a 0,50 é muito boa; de 0,50 a 1,00 é boa; de 1,00 a 2,00 regular, e acima de 2,00 não deve ser usada para papel, tendo em vista se tratar de fibras com paredes espessas ou muito espessas. O Índice de Runkel bem como a fração parede são relacionados à rigidez das fibras, em que, maiores valores implicam em que mais rígida será a fibra, mostrando correlação direta com as características finais de resistência do papel (GONÇALEZ et al., 2014).

A fração de parede é um valor que indica a rigidez da fibra e associa-se à facilidade de colapso e à flexibilidade para ligação das fibras (BOSCHETTI et al., 2015). Os valores observados, próximos de $46 \%$, classificam a fibra acima do limite $(40 \%)$ indicado para uma satisfatória qualidade da celulose, em que fibras com índice próximos aos observados apresentam-se muito rígidas, com baixa flexibilidade, dificultando a interlocução com outras fibras, resultando assim em pior resistência do papel confeccionado (FOELKEL; BARRICHELO, 1975). A fração parede das fibras branqueadas também exerce influência nas propriedades do papel. Menegazzo (2012) relata que fibras com maior fração parede são rígidas e mais difíceis de colapsarem. Assim, a ligação entre fibras e a consolidação da folha de papel são prejudicadas, dando origem a papéis mais porosos, volumosos, rugosos e absorventes.

O coeficiente de flexibilidade da Hevea brasiliensis se encontra próximo a 54\%. Segundo Foelkel e Barrichelo (1975), os maiores valores desse coeficiente caracterizam as fibras mais flexíveis, facilitando as ligações entre as mesmas, 
acrescentando resistência ao papel. Por outro lado, o valor obtido para esse coeficiente está distante da faixa recomendada, próxima a 80\% (NISGOSKI et al., 2012). Ainda segundo os autores, pode-se relacionar o nível de colapso sofrido pelas fibras quando do momento da confecção do papel com o índice de flexibilidade, em que maiores valores resultaram em maior resistência à ruptura e menor valor à tração.

O índice de enfeltramento prediz sobre a resistência das fibras ao rasgo e dobras duplas e almejam-se fibras que apresentem valor acima de 50 para tal parâmetro (FOELKEL; BARRICHELO, 1975). O IE obtido para a espécie em estudo foi de 54, se encontrando próximo se comparado à Calycophyllum multiflorum e Cedrela fissilis, com IE de aproximadamente 53 (BENITES et al., 2015). Na Tabela 3 observa-se os valores médios de densidade básica para a madeira de Hevea brasiliensis.

TABELA 3. Variação da densidade no sentido base-topo para a madeira de Hevea brasiliensis.

\begin{tabular}{lc}
\hline Altura $(\mathbf{m})$ & Densidade Básica \\
\cline { 2 - 2 } & $\left(\mathbf{g} / \mathbf{c m}^{\mathbf{3}}\right)$ \\
\hline 0 & $0,559^{(0,008)} \mathrm{A}$ \\
4,5 & $0,543^{(0,012)} \mathrm{A}$ \\
9 & $0,532^{(0,013)} \mathrm{A}$ \\
13,5 & $0,530^{(0,017)} \mathrm{A}$ \\
18 & $0,544^{(0,033)} \mathrm{A}$ \\
$*$ Médias seguidas de mesma letra são \\
estatisticamente iguais, pelo teste de Tukey \\
a 95\% de probabilidade. Desvio padrão entre \\
parênteses.
\end{tabular}

Observa-se na Tabela 3 que todos os tratamentos estudados mostraram-se estatisticamente iguais para a propriedade densidade básica no sentido base-topo. A descoberta das propriedades inerentes da espécie em estudo, como a densidade básica, relaciona-se diretamente com os resultados de polpação. A densidade básica é de grande importância para determinação da qualidade final do papel e celulose, juntamente com a composição química e a morfologia das fibras.

É possível indicar utilizações da espécie em trabalho usando como parâmetro sua respectiva massa específica básica, podendo relacioná-la com indicações de uso, transporte e manuseio da espécie. De uma forma geral, os valores encontrados para os diversos tipos de densidade são bastante homogêneos. Os resultados verificados para a análise estatística (ANOVA), para os resultados de densidade básica indicaram não haver diferença significativa. Valores similares foram observados por Riyaphan et al. (2015), apresentando densidade básica média de $0,551 \mathrm{~g} / \mathrm{cm}^{3}$.

Visando a fabricação de polpa celulósica, Dias e Simonelli (2013) recomendaram o uso de madeiras com densidade básica entre 0,400 e 0,550 g. $\mathrm{cm}^{-3}$. Ainda segundo os autores, madeiras com densidade inferior a 0,40 levam a redução de rendimento, maior consumo de reagentes e elevado teor de rejeitos, enquanto que densidades superiores a 0,55 apresentam maior dificuldade de picagem das toras, o que acarreta além do maior desgaste das facas picadoras, maior proporção de cavacos de grandes dimensões, dificultando a impregnação do licor nestes e 
levando a uma menor produção de polpa depurada. Na Figura 3 estão apresentados os teores médios dos componentes químicos da espécie Hevea brasiliensis.

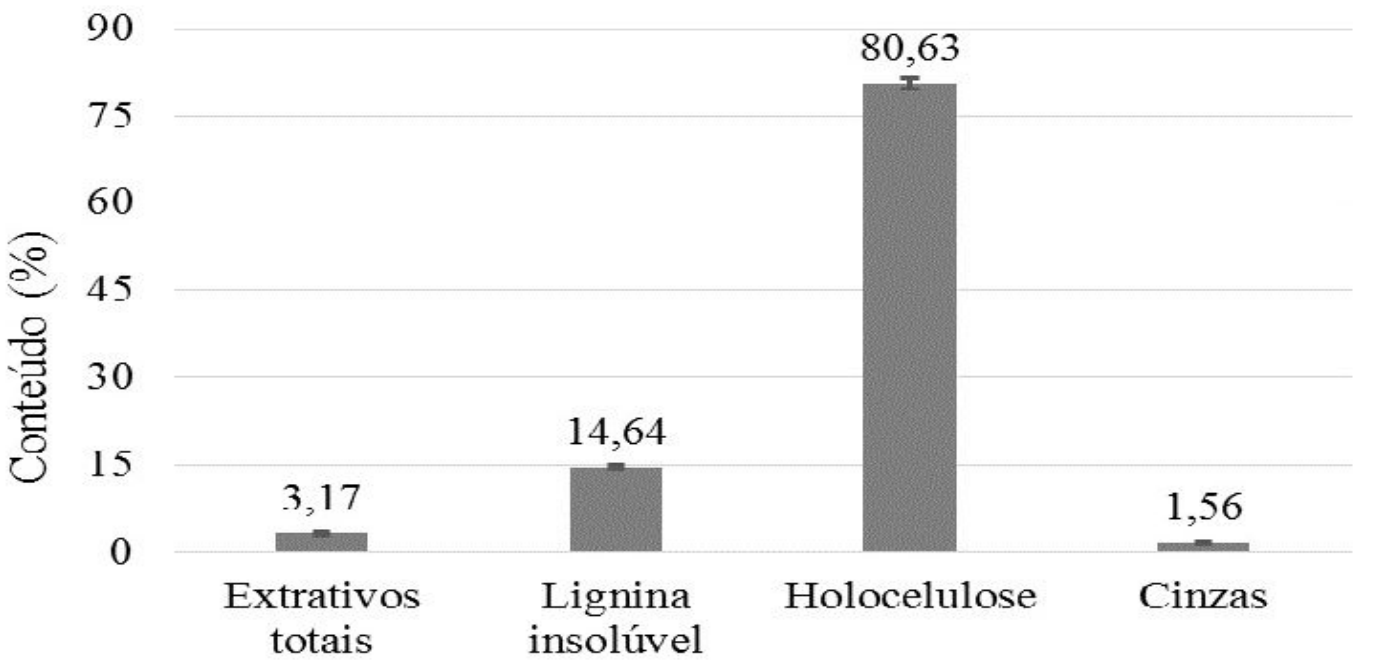

FIGURA 3. Componentes químicos da madeira de Hevea brasiliensis.

O produto final de uma fábrica de celulose sofre influência dos constituintes químicos da espécie de madeira, sendo necessário a sua caracterização (DIAS; SIMONELLI, 2013). Ainda segundo os autores, a constituição química da madeira é classificada pelos componentes fundamentais que são os constituintes macromoleculares como celulose, hemiceluloses e a lignina, que representam cerca de $95 \%$ da estrutura total da madeira, já os outros $5 \%$ são classificados como compostos que não formam parte essencial da estrutura da madeira, denominados extrativos e cinzas.

Os teores médios de extrativos totais obtidos mostraram-se inferiores aos encontrados por Riyaphan et al. (2015), para árvores de Hevea brasiliensis, provenientes da Malásia, cujos valores médios foram de $9 \%$. O teor de extrativos da madeira é de fundamental importância visando a fabricação de celulose, pois resulta em maior demanda de reagentes químicos na polpa celulósica, com consequente redução do rendimento, inibições de reações, incrustações de materiais na polpa e nos equipamentos, corrosão e dificuldades no branqueamento (GOMES, 2007).

Para Raia (2017), os teores médios encontrados para a lignina insolúvel variaram de $21,41 \%$ a $6,0 \mathrm{~m}$ de altura na árvore de Hevea brasiliensis, mostrando assim superior ao presente estudo. Maranesi (2010) enfatiza que a lignina é o composto mais indesejável presente no lenho visando a produção da pasta celulósica, pois exige maior quantidade de álcali para a deslignificação, implicando em maior degradação dos carboidratos e dissolução dos polissacarídeos de baixo peso molecular, o que provoca a redução no rendimento, na viscosidade da polpa e na resistência física, além de gerar maior quantidade de sólidos para ser queimada na caldeira.

Diante dos teores verificados para holocelulose, o presente estudo se mostra superior aos teores relatados por Raia (2017), os quais variaram de $70,60 \%$ na base a $74,20 \%$ a $6 \mathrm{~m}$ de altura, sendo as médias estatisticamente diferentes. Neste experimento a concentração de holocelulose apresentou tendência de diminuição com a altura. Um bom teor de holocelulose é primordial para a confecção de papel. 
Tendo como base o teor de cinzas, Raia (2017) obteve 1,18\% na altura de $3 \mathrm{~m}$, valores inferiores quanto ao estudo. Salienta-se que o teor de cinzas é indesejável em grandes proporções, devido ao desgaste ocasionado no maquinário.

\section{CONCLUSÃO}

Com base nos resultados observados, pode-se concluir que:

A espécie apresentou bons resultados para as propriedades anatômicas avaliadas, apresentando potencial para ser utilizada na confecção de papel e celulose. Os índices de fração parede e coeficiente de enfeltramento ficaram altos e baixos, respectivamente, podendo interferir drasticamente nas propriedades finais do produto.

A densidade básica obtida para a espécie em estudo possibilitou a sua classificação como madeira de média densidade, onde o teste Tukey não identificou diferenças entre as médias para esta propriedade da madeira no sentido base-topo. O valor obtido para densidade básica permite inserir a espécie em estudo como espécie com potencial utilização para produção de papel e celulose, devido serem recomendados valores de densidade básica entre 0,40 e $0,55 \mathrm{~g} / \mathrm{cm}^{3}$.

Os teores dos constituintes químicos da madeira se mostraram satisfatórios visando a produção de papel e celulose, apresentando altos valores de holocelulose, principal constituinte químico para essa finalidade. Os teores de extrativos e cinzas se mostraram abaixo de $5 \%$, como descrito em vários trabalhos com valores de referência para fabricação de papel e celulose.

\section{REFERÊNCIAS}

ANDRADE, L. M. F.; SCATOLINO, M. V.; FARIA, D. L.; CÉSAR, A. A.; MENDES, L. M.; GUIMARÃES JÚNIOR, J. B. Inclusão do resíduo de polpação da celulose na produção de painéis aglomerados de média densidade. Scientia Forestalis, v. 46, n. 120, p. 626-637, 2018.

ABNT - Associação Brasileira de Normas técnicas. NBR 11941: Madeira: Determinação da densidade básica. Rio de Janeiro. 2003, 6p.

ABNT - Associação Brasileira de Normas técnicas. NBR 13999: Papel, cartão, polpas e madeira - Determinação do resíduo (cinza) na ignição a $525^{\circ} \mathrm{C}$. Rio de Janeiro; 2017, 5p.

ABNT - Associação Brasileira de Normas técnicas.- NBR 14853: Madeira Determinação da matéria solúvel em etanol-tolueno e em diclorometano e em acetona. Rio de Janeiro; 2010, 3p.

ABNT - Associação Brasileira de Normas técnicas. NBR 7989: Polpa e madeira Determinação de lignina insolúvel em ácido. Rio de Janeiro; 2010, 6p.

BALDIN, T.; MARCHIORI, J. N. C.; NISGOSKI, S.; TALGATII, M.; DENARDI, L. Anatomia da madeira e potencial de produção de celulose e papel de quatro espécies jovens de Eucalyptus L'Hér. Ciência da Madeira, v. 8, n. 2, p. 114-126, 2017.

BENITES, P. K. R. M.; GOUVÊA, A. F. G.; CARVALHO, A. M. M. L.; SILVA, F. C. Caracterização anatômica das fibras de oito espécies florestais do Cerrado de Mato 
Grosso do Sul para a produção de papel. Ciência da Madeira, v. 6, n. 2, p. 88-93, 2015.

BONDUELLE, G. M.; IWAKIRI, S.; TRIANOSKI, R.; PRATA, J. G. \& DA ROCHA, V. $Y$. Análise da massa específica e da retratibilidade da madeira de Tectona grandis nos sentidos axial e radial do tronco. Revista Floresta, v. 45, n. 4, p. 671-680, 2015.

BOSCHETTI, W. T. N.; PAES, J. B.; OLIVEIRA, J. T. S.; DUDECKI, L. Características anatômicas para produção de celulose do lenho de reação de árvores inclinadas de eucalipto. Pesquisa agropecuária brasileira, v. 50, n. 6, p. 459-467, 2015.

BURGER, L. M.; RICHTER, H. G. Anatomia da madeira. São Paulo: Nobel; $1991.154 \mathrm{p}$.

DIAS, O. A.; SIMONELLI, G. Qualidade da madeira para a produção de celulose e papel. Enciclopédia Biosfera, v. 9, n. 17, p. 3632-3646, 2013.

FOELKEL, C. E. B.; BARRICHELO, L. E. G. Relações entre características da madeira e propriedades da celulose e papel. O Papel, v. 36, n. 9, p. 49- 53, 1975.

FRANÇA, T. S. F. A.; ARANTES, M. D. C.; PAES, J. B.; VIDAURRE, G. B.; OLIVEIRA, J. T. S.; BARAÚNA, E. E. P. Características anatômicas e propriedades físico-mecânicas das madeiras de duas espécies de mogno africano. Cerne, Lavras, v. 21 , n. 4 , p. $633-6402015$.

FREITAS, P. C. E.; SETTE JR, C. R.; CASTRO, V. R.; TOMAZELLO FILHO, M.; CHAIX, G. \& LACLAU, J. P. Efeito da disponibilidade hídrica e da aplicação de potássio e sódio nas características anatômicas do lenho juvenil de Eucalyptus grandis. Revista Árvore, v. 39, n. 2, p. 405-416, 2015.

GALLIO, E.; SANTINI, E. J.; GATTO, D. A.; DE SOUZA, J. T.; RAVASI, R.; DE MENEZES, W. M.; FLOSS, P. A.; BELTRAME, R. Caracterização Tecnológica da Madeira de Eucalyptus benthamii Maiden et Cambage. Revista Scientia Agraria Paranaensis, v. 15, n. 3, p. 244-250, 2016.

GAMA, A. T.; CABACINHA, C. D.; MEIRA, M. R.; LEITE, M. V. S. Variações da densidade básica da casca e da madeira do barbatimão (Stryphnodendron adstringens (Mart.) Coville). Enciclopédia Biosfera, v. 10, n. 18, p. 3027-3038, 2014.

GARBIN, M.; CHIARAMONTE, R. C.; CALHEIRO, D.; MORAES, C. A. M.; MODOLO, R. C. E. Colheita mecanizada do eucalipto para produção de celulose na perspectiva da avaliação do ciclo de vida. Revista Latino-americana em avaliação do ciclo de vida, v. 1, n. 1, p. 86-111, 2017.

GIL, J. L. R. A.; BARBOZA, F. S.; CONEGLIAN, A.; SILVA, M. F.; MORAES, M. D. A.; SETTE JÚNIOR, C. R. Características físicas e anatômicas da madeira de Tectona grandis L.f. aos 7 anos de idade. Revista de Ciências Agrárias de Portugal, v. 41, n. 2, p. 529-538, 2018. 
GOMES, A. F. Avaliação das características da madeira e da polpa de Eucalyptus mediante a aplicação de métodos não destrutivos na árvore viva. 2007. 141f. Dissertação (Mestrado em Engenharia Florestal). Universidade Federal de Lavras, Lavras, 2007.

GONÇALEZ, J. C.; SANTOS, G. L.; SILVA JUNIOR, F. G.; MARTINS, I. S.; COSTA, J. A. Relações entre dimensões de fibras e de densidade da madeira ao longo do tronco de Eucalyptus urograndis. Scientia Forestalis, v. 42, n. 101, p. 81- 89, 2014.

IBGE - Instituto Brasileiro de Geografia e Estatística. Produção Agrícola Municipal - Culturas temporárias e permanentes, 2017.

INTERNATIONAL ASSOCIATION OF WOOD ANATOMY. List of microscopic features hardwood identification. IAWA Bulletin, v.10, n.3, p.220-359, 1989. Disponível em: $<$ https://www.researchgate.net/publication/294088872_IAWA_List_of_Microcopie_Fe atures_for_Hardwood_Identification>.

LIMA, R. DA S.; COELHO J. C. F.; SILVA J. C.; ARAÚJO J. DE A.; CALDERON, C. M. A. Influência da anatomia nas propriedades físicas da madeira de Iryanthera grandis Ducke. Revista Enciclopédia Biosfera, v. 10, n. 19, p. 1188, 2014.

MARANESI, G. L. Influência de variáveis do processo de produção industrial na qualidade da polpa Kraft de eucalipto. 2010. 87f. Dissertação (Mestrado Profissional em Tecnologia de Celulose e Papel) - Universidade Federal de Viçosa, Viçosa, 2010.

MENEGAZZO, M. L. Características morfológicas de celuloses branqueadas de Pinus e Eucalyptus em analisador óptico automático de fibras. 2012. 65f. Dissertação (Mestrado em Ciências Florestais) - Faculdade de Ciências Agronômicas de Botucatu, Universidade Estadual Paulista "Julio de Mesquita Filho", Botucatu, 2012.

MOKFIENSKI, A.; COLODETTE, J. L.; GOMIDE, J. L.; CARVALHO, A. M. M. L. A importância relativa da densidade da madeira e do teor de carboidratos no rendimento da polpa e na qualidade do produto. Ciência Florestal, v.18, p.401-413. 2008.

NISGOSKI, S.; MUÑIZ, G. I. B.; TRIANOSKI, R.; MATOS, J. L. M.; VENSON, I. Características anatômicas da madeira e índices de resistência do papel de Schizolobium parahyba (Vell.) Blake proveniente de plantio experimental. Scientia Forestalis, v. 40, n. 94, p. 203-211, 2012.

PAULA, J. E. Caracterização anatômica de madeiras nativas do cerrado com vistas à produção de energia. Cerne, v. 5, n. 2, p. 26-40, 1999.

PINATI, E.; FARIA, D. L.; MENDES, R. F.; MENDES, L. M.; PROTÁSIO, T. P.; GUIMARÃES JÚNIOR, J. B. Painéis compensados sarrafeados produzidos com 
Pinus oocarpa, Castilla ulei e Acrocarpus fraxinifolius. Ciência da Madeira, v. 9, n. 3, p. 199-208, 2018.

RAIA, R. Z. Laminação e produção de painéis compensados de Hevea brasiliensis - Clone RRIM600. 2017. 92f. Dissertação (Mestrado em Engenharia Florestal) - Universidade Federal do Paraná, Curitiba, 2017.

RAMOS, L. M. A.; LATORRACA, J. V. F.; LIMA, H. R. P.; SANTOS, G. C. V. Variação intraespecífica na anatomia do lenho de Hevea brasiliensis (Willd. ex A. Juss.) Mull. Arg. relacionada à extração de látex. Floresta, v. 48, n. 2, p. 255-264, 2018.

RIYAPHAN, J.; PHUMICHAI, T.; NEIMSUWAN, T.; WITAYAKRAN, S.; SUNGSING, K.; KAVEETA, R.; PHUMICHAI, C. Variability in chemical and mechanical properties of Pará rubber (Hevea brasiliensis) trees. ScienceAsia, Nakhon Pathom, v. 41, n. 4, p. 251-258, 2015.

ROBERT, N. T. F. Produção de Embalagem de Papel. Dossiê Técnico. Serviço Brasileiro de Respostas Técnicas - SBRT, p. 16, 2007.

SEGUNDINHO, P. G. A.; GONÇALVES, F. G.; GAVA, G. C.; TINTI, V. P.; ALVES, S. D.; REGAZZI, A. J. Eficiência da colagem de madeira tratada de Eucalyptus cloeziana F. Muell para produção de madeira laminada colada (MLC). Revista Matéria, v. 22, n. 2, 2017.

VIVIAN, M. A.; SEGURA, T. E. S.; BONFATTI JÚNIOR, E. A.; SARTO, C.; SCHMIDT, F.; SILVA JÚNIOR, F. G.; GABOV, K.; FARDIM, P. Qualidade das madeiras de Pinus taeda e Pinus sylvestris para a produção de polpa celulósica kraft. Scientia Forestalis, v. 43, n. 105, p. 183-191, 2015. 